\title{
Data Analysis of Hybrid Principal Component for Rural Land Circulation Management based on Gray Relation Algorithmic Models
}

\author{
Zhongbo Wang and Zhilin Suo* \\ College of Economics and Management, Northeast of Agricultural University, Harbin, 150001, China
}

\begin{abstract}
Data analysis is a common and essential process of determining the main driving factors of hybrid information principal components for rural land circulation management. To solve the existing hybrid information regarding the problem of rural land circulation in China, the main driving factors need to be confirmed based on gray relation algorithmic models in the paper. Five types of gray relation algorithmic models are adopted for hybrid Information principal component analysis for rural land circulation, such as the Deng's gray relation algorithmic model, gray absolute relation algorithmic model, T-type gray relation algorithmic model, improved gray relation algorithmic model, and gray slope relation algorithmic model. According to our collected data, the results of data analysis comparison illustrate that different gray relation algorithms may affect the order of the importance of each driving factor. The most critical driving factors are obtained as follows: the rate of non-agricultural income, the ratio of signed contracts and the ratio of peasants' spontaneous taking part in rural land circulation, which are also the most three main driving factors on the Chinese rural land circulation management.
\end{abstract}

Keywords: data analysis; quality management; rural land circulation; gray relation analysis; principal component analysis; algorithmic model

(Submitted on March 13, 2019; Revised on April 8, 2019; Accepted on June 20, 2019)

(C) 2019 Totem Publisher, Inc. All rights reserved.

\section{Introduction}

Usually, it is difficult to determine the main factors affecting the development of a complex hybrid information system. In 1982, Deng proposed the gray system theory, which combines the advantages of system theory, information theory, and cybernetics. It can effectively extract valuable information from limited information in an uncertain system with a small number of samples and make an effective description of the development for a complex hybrid information system [1].

When analyzing a complex hybrid information system, the primary and secondary factors that enhance or restrict the development of the system should be analyzed and distinguished. Gray relation analysis (GRA) theory can be used to quantify the importance of the factors in the complex hybrid information system based on a small number of samples. The GRA method has been applied in many fields. It can be used to evaluate the effectiveness of programs [2] and predict software defects [3]. In order to quantify the relationship between different factors, various forms of correlation coefficients have been proposed, such as the canonical correlation coefficient and resemblance correlation coefficient. These correlation coefficients are obtained based on the mathematical statistic theory and require a large number of samples. However, in practice, it is hard to meet this requirement because the amount of statistical data is limited. Therefore, the method based on mathematical statistic theory is not suitable to analyze the main factors in a complex hybrid information system based on a small number of samples. Aiming at the above problem, the GRA method can effectively overcome this shortcoming, and there is no requirement for the sample size and data distribution [4]. The following models are some commonly used gray relation algorithms. One of the most fundamental models is Deng's gray relation analysis model, proposed by Deng Julong based on the gray relation analysis axiom [5-6]. The B-type gray relation analysis (B-GRA) was proposed by Wang Qingyin (1989) according to the proximity and similarity between two objects [7]. The gray absolute relation grade (GARG) model was proposed by Mei Zhenguo in 1992 based on the adjacency degree of absolute trends and relative trends between two time series curves. The T-type gray relation analysis (T-GRA) model was proposed by Tang Wuxiang in 1995 based on the

* Corresponding author.

E-mail address: szl1960@ sina.com 
approaching degree between two time series curves [8-10]. The gray slope relation grade (GSRG) model was proposed by Dang Yaoguo in 1994 and later developed by Dang Yaoguo and Sun Yugang in 2007 [11-13]. The generalized gray relation grade was discussed based on the generalized interval by Wang Qingyin and Guo Litian in 2005 [14]. The defects of gray relation grade have been discussed, and some corresponding improvements have been proposed [15-20]. The contradiction of the GRA axiom was pointed out and proven [21], which means that the GRA axiom is imperfect to define the GRA. However, the advantage of the above methods is that there is no need for the quantity and regularity of the samples, and there is also no need to consider the coupling symmetry and wholeness in the practical application. Therefore, the above GPA methods have been widely used to analyze the hybrid information principal components. In reference [22], the GRA method was used to exploit the relationship between the shipping exchange and port economy. In reference [23], different levels of combinations of the factors were ranked based on the GRA method. In reference [24], the security risk of information systems based on D-S theory and the GRA method was assessed. In reference [25], the GRA method was used to select the appropriate business manager. In reference [26], the GRA theory was used to analyze the main factors of corrosion of oil tubes. In reference [27], the GRA method was used to exploit the turning operation being affected by cutting parameters and the tool nose radius. In reference [28], information security controls were evaluated based on the GRA method. In reference [29], the GRA method was used to conduct the proper parameters in the application of single point incremental forming.

In China, the problem of rural land circulation has been widely concerned. Policies regarding land management rights have been mentioned in the "NO.1 Central Document" for over a decade from 2005 to 2016. "Three Rural Issues" have always been crucial issues related to the development of the society, politics, and economy. The problem of rural land circulation has also aroused great concern in academia. Many scholars have studied rural land circulation in economics, sociology, and political science. The driving factors that promote the rural land circulation in microcosm mainly depend on the farmers' attitudes. Usually, correlation analysis, regression analysis, and other statistical methods are used to analyze the main factors that can influence the rate of rural land circulation. These methods require a large number of surveys and effective data as support, and the sample data must obey a typical probability distribution to some extent [30].

This paper introduces some related concepts of GRA and several typical GRA models. The main factors influencing rural land circulation by using GRA theory are analyzed, in which relevant data in certain rural areas during the period from 2004 to 2009 are taken as example.

\section{Gray Relation Analysis}

The fundamental of GRA is to calculate the multiple factors GRG by comparing the degree of similarity of the geometry between two statistical series curves in a system. The lower the difference of geometry between the two sequence curves, the greater their correlation degree.

\subsection{The Basic Concept of GRA}

Before analyzing a complex hybrid information system, some features that can reflect the system should be selected. The data sequences that reflect the features' behavioral tendency are mapping vectors, which represent the system behavior indirectly. Some basic concepts of GRA are defined as follows.

1) The reference sequence is as follows. If $X_{0}$ is the variable that reflects the system behavior and $x_{0}(k)$ is the data of the sequence number $k(k=1,2, \cdots, n)$, and $X_{0}(k)=\left(x_{0}(1), x_{0}(2), \cdots, x_{0}(n)\right)$ is the reference sequence of the system.

2) The objective sequence is as follows. Let $X_{i}$ be the system factors and $x_{i}(k)$ represent the observation data of the serial number $k(k=1,2, \cdots, n)$, and $X_{i}(k)=\left(x_{i}(1), x_{i}(2), \cdots, x_{i}(n)\right)$ is the objective sequence of the system.

3) The gray relation coefficient is the measure of the comparison between $x_{0}(k)$ and $x_{i}(k)$.

4) The gray relation grade is the correlation degree between $X_{0}$ and $X_{i}$, and it can be written as $\gamma\left(X_{0}, X_{i}\right)$.

5) The gray relation ordinal is as follows. If $\gamma\left(X_{0}, X_{i}\right)$ is bigger than $\gamma\left(X_{0}, X_{j}\right)$, then $X_{i} \succ X_{j} \succ$ is called the gray relation ordinal derived from GRG [31]. 


\subsection{Nondimensionalization}

After the system features and the system behavioral influencing factors are defined, the mapping vectors need to be dealt with properly before quantitative analysis, by turning them into non-dimensional data with similar order of magnitude [32]. The processing is the first step of gray system analysis and modeling. The data from a large amount of information and statistics through different channels is usually called raw data. The order of magnitude and the units of the measurement of the raw data are different, and they cannot be calculated directly. These raw data has the following characteristics [33].

1) Most of the dimensions are different because the indictors are different, even if the dimensions are same, and the orders of magnitude may be hugely different.

2) Most of the data is scattered and has evident randomness.

3) Most of the data has a gray degree because the information is incomplete and vague.

If the data is used to analyze the system directly, the calculation will be distorted and the analysis results will be deviated. To guarantee the quality of the model and the reliability of analysis results, some kinds of mathematical methods should be used to transform the raw data, and this process is called data preprocessing. The processed data should meet the following requirements.

1) The dimension of data used to analyze the system is unified.

2) The order of magnitude of factors or sequences can be compared.

3) The processed data can show its rudimentary distribution trend.

4) The nonlinear relationship between the factors is transformed into a linear relationship as much as possible.

Single Index Sequence Transformation:

1) Initial transformation (IT):

$$
X D_{1}=\left(\frac{x(1)}{x(1)}, \frac{x(2)}{x(1)}, \cdots, \frac{x(n)}{x(1)}\right)
$$

Where $x(1) \neq 0, k=1,2, \cdots, n$.

2) Mean transformation (MT):

$$
X D_{2}=\left(\frac{x(1)}{\bar{X}}, \frac{x(2)}{\bar{X}}, \cdots, \frac{x(n)}{\bar{X}}\right)
$$

Where $\bar{X}=\frac{1}{n} \sum_{k=1}^{n} x(k), \bar{X} \neq 0, k=1,2, \cdots, n$.

3) Multiple transformation (MULT):

$$
X D_{3}=\left(\frac{x(1)}{\min x(k)}, \frac{x(2)}{\min x(k)}, \cdots, \frac{x(n)}{\min x(k)}\right)
$$

Where $k=1,2, \cdots, n$.

4) Normalization transformation (NT):

$$
X D_{4}=\left(\frac{x(1)}{x_{0}}, \frac{x(2)}{x_{0}}, \cdots, \frac{x(n)}{x_{0}}\right)
$$


Where $x_{0}$ is a constant that is bigger than zero, $k=1,2, \cdots, n$.

5) Range maximization transformation (RMT):

$$
X D_{5}=\left(\frac{x(1)-\min x(k)}{\max x(k)-\min x(k)}, \cdots, \frac{x(n)-\min x(k)}{\max x(k)-\min x(k)}\right)
$$

Where $k=1,2, \cdots, n$.

If the single index sequence is $X=(x(1), x(2), \cdots, x(n))$, the sequence transformation should have the following qualities.

$$
\begin{aligned}
& x(k) d_{1}=x(k) / x(1) \\
& x(k) d_{2}=x(k) / \bar{X} \\
& x(k) d_{3}=x(k) / \min x(k) \\
& x(k) d_{4}=x(k) / x_{0} \\
& x(k) d_{5}=(x(k)-\min x(k)) /(\max x(k)-\min x(k))
\end{aligned}
$$

1) If $x(k) \geq 0$, then $x(k) d_{j} \geq 0, j=1,2, \cdots, 5$;

2) If $x\left(k_{1}\right), x\left(k_{2}\right) \in X$ and $x\left(k_{1}\right)>x\left(k_{2}\right)$, then $x\left(k_{1}\right) d_{j} \geq x\left(k_{2}\right) d_{j}, j=1,2, \cdots, 5$;

3) If $x\left(k_{1}\right), x\left(k_{2}\right) \in X$ and $x\left(k_{1}\right)<x\left(k_{2}\right)$, then $x\left(k_{1}\right) d_{j}<x\left(k_{2}\right) d_{j}, j=1,2, \cdots, 5$;

4) If $x\left(k_{1}\right), x\left(k_{2}\right), x\left(k_{3}\right), x\left(k_{4}\right) \in X$, then $\frac{x\left(k_{1}\right)-x\left(k_{2}\right)}{x\left(k_{3}\right)-x\left(k_{4}\right)}=\frac{x\left(k_{1}\right) d_{j}-x\left(k_{2}\right) d_{j}}{x\left(k_{3}\right) d_{j}-x\left(k_{4}\right) d_{j}}, j=1,2, \cdots, 5$.

\section{Typical GRA}

If the reference sequence is $X_{0}=\left(x_{0}(1), x_{0}(2), \cdots, x_{0}(n)\right)$, the objective sequence is $X_{i}=\left(x_{i}(1), x_{i}(2), \cdots, x_{i}(n)\right)$, and $(i=1,2, \cdots, m) . \varepsilon_{0 i}(k)$ is the gray relation coefficient (GRC) $(k=1,2, \cdots, n)$, and $\gamma\left(X_{0}, X_{i}\right)$ is the gray relation grade.

\subsection{Deng's Gray Relation Grade}

Deng's gray relation grade (GRG) is a commonly used method that was proposed by Deng Julong. It is applied to denote the relation degree between multiple factors in gray systems [34].

GRC is as follows:

$$
\varepsilon_{0 i}(k)=\frac{m m+\rho \cdot M M}{\left|x_{0}(k)-x_{i}(k)\right|+\rho \cdot M M}
$$

GRG is as follows:

$$
\gamma\left(X_{0}, X_{i}\right)=\frac{1}{n} \cdot \sum_{i=1}^{n} \varepsilon_{0 i}(k)
$$

Where $m m=\min _{i} \min _{i}\left|x_{0}(k)-x_{i}(k)\right|, M M=\max _{i} \max _{i}\left|x_{0}(k)-x_{i}(k)\right|$, and $\rho \in(0,+\infty) . \rho$ is the distinguishing coefficient. The smaller the $\rho$, the stronger the distinguishing capability, and usually $\rho=0.5$. 
Deng's gray relation model fully reflects the constraint condition of the GRA axiom. The calculation focuses on the influence of the distance between two points on the relation degree. However, the main disadvantages are as follows: the relation degree lacks normalization; both GRC and GRA are likely to be affected by $\rho$; only the positive correlation, rather than the negative correlation, between two curves can be reflected; and it does not have isotonicity after the nondimensional disposal [35-36].

\subsection{Gray Absolute Relation Analysis (GARA)}

In 1992, Mei Zhenguo proposed gray absolute relation grade (GARG) according to the proximity degree of the changing tendency of the factors' time series curves [37].

If the references are not the same or the references cannot be compared, the disadvantages of Deng's GRA may occur. The gray absolute relation analysis method can solve the above problem.

The GARG is as follows.

$$
\begin{gathered}
\gamma\left(X_{0}, X_{i}\right)=\frac{1+\left|s_{0}\right|+\left|s_{i}\right|}{1+\left|s_{0}\right|+\left|s_{i}\right|+\left|s_{i}-s_{0}\right|} \\
\left|s_{0}\right|=\left|\sum_{k=2}^{n-1} x_{0}(k)+\frac{1}{2} x_{0}(n)\right|,\left|s_{i}\right|=\left|\sum_{k=2}^{n-1} x_{i}(k)+\frac{1}{2} x_{i}(n)\right| \\
\left|s_{i}-s_{0}\right|=\left|\sum_{k=2}^{n-1}\left[x_{i}(k)-x_{0}(k)\right]+\frac{1}{2}\left[x_{i}(n)-x_{0}(n)\right]\right|
\end{gathered}
$$

It mainly studies the relationship between the absolute increments of two sequences and measures the relevance between two sequences by the area between two lines. The GARG overcomes some disadvantages of Deng's GRA and disuses the distinguishing coefficient. However, this method cannot satisfy the normalization requirement and does not possess isotonicity after non-dimensional disposal.

\subsection{Improved Gray Slope Relation Analysis}

In 1994, Dang Yaoguo improved the GRA model based on the GARA model and Deng's GRA model. The improved gray slope relation analysis method overcomes some disadvantages of the gray absolute relation model. In addition, some patented inventions based on gray relation analysis have also made some effective improvements to the traditional gray relation analysis method [38].

The GSRC is as follows.

$$
\gamma\left(X_{0}, X_{i}\right)=\frac{1}{n-1} \sum_{j=1}^{n-1}\left\{k_{i j} c /\left[c+\operatorname{tg}\left(U_{j} / 2\right)\right]\right\}
$$

Where

$$
\begin{gathered}
k_{i j}=1-\frac{\left|X_{i}(k)-X_{0}(k)\right|}{\sum_{k=1}^{n}\left|X_{i}(k)-X_{0}(k)\right|} \\
U_{j}=\operatorname{arctg}\left[\frac{\left(X_{i}(k+1)-X_{i}(k)\right)-\left(X_{0}(k+1)-X_{0}(k)\right)}{1+\left(X_{i}(k+1)-X_{i}(k)\right) \cdot\left(X_{0}(k+1)-X_{0}(k)\right)}\right]
\end{gathered}
$$




\subsection{T-Type Gray Relation Analysis}

In 1995, T-type gray relation analysis (T-GRA), which can reflect positive correlation and negative correlation between two curves, was proposed by Tang Wuxiang based on the adjacency degree of the relative trends of factors' time series curves [39].

The T-GRA is as follows.

$$
\gamma=\frac{1}{n-1} \sum_{k=2}^{n} \varepsilon_{0 i}(k)
$$

Where

$$
\begin{gathered}
\varepsilon_{0 i}(k)=\left\{\begin{array}{cc}
\operatorname{sgn}\left(\Delta y_{0}(k) \cdot \Delta y_{i}(k)\right) \frac{\min \left(\left|\Delta y_{0}(k)\right|, \Delta y_{i}(k)\right)}{\max \left(\left|\Delta y_{0}(k)\right|, \Delta y_{i}(k)\right)}, & \Delta y_{0}(k) \cdot \Delta y_{i}(k) \neq 0 \\
0, & \Delta y_{0}(k) \cdot \Delta y_{i}(k)=0
\end{array}\right. \\
D_{0}=\frac{1}{n-1} \sum_{k=2}^{n}\left|\Delta x_{0}(k)\right|=\frac{1}{n-1} \sum_{k=2}^{n}\left|x_{0}(k)-x_{0}(k-1)\right|, k=2,3, \cdots, n \\
\Delta y_{0}(k)=\frac{x_{0}(k)-x_{0}(k-1)}{D_{0}} \\
\Delta y_{i}(k)=\frac{x_{0}(k)-x_{i}(k-1)}{D_{0}}
\end{gathered}
$$

Its disadvantage is that the relation of certain increments would be magnified or weakened if all the data is process dimension regardless of the situation, which will result in a wrong conclusion.

\subsection{Gray Slope Relation Analysis}

In 1994, Dang Yaoguo proposed the gray slope relation grade (GSRG), and this method calculates the degree according to the adjacency degree of the average relative trends of the factors' time series curves [40-41].

The GSRC is as follows.

$$
\gamma\left(X_{0}, X_{i}\right)=\frac{1}{n-1} \sum_{k=1}^{n-1} \varepsilon_{0 i}(k)
$$

Where

$$
\varepsilon_{0 i}(k)=\frac{1}{1+\left|\frac{x_{i}(k+1)-x_{i}(k)}{x_{i}(k+1)}-\frac{x_{0}(k+1)-x_{0}(k)}{x_{0}(k+1)}\right|}
$$

Although the GSRG has isotonicity after non-dimensional disposal, it cannot satisfy the normalization requirement or reflect the negative correlation of the factors.

In fact, the definition of relation grade is not ideal; it measures the relation degree between factors according to the adjacency degree of the data columns' geometry and trends only. Many relation grade formulas can be established when researching the relation degree between factors according to the idea of similar geometry. The analysis based on the formulas mentioned above does not lead to the same conclusion. Therefore, it would be better to run calculations of diverse types. 
In practical work, the sensitivity of gray relation ordinal should be noticed. When using different non-dimensional methods to transform the raw data and different distinguishing coefficients, the order of the gray relation ordinal will be different. How to determine the objective standard for gray relation grades and which kind of non-dimensional method should be chosen are the problems.

\section{Parameters Estimation in GLD}

Figure 1 is the analysis chart of the main factors of rural land circulation based on GRA.

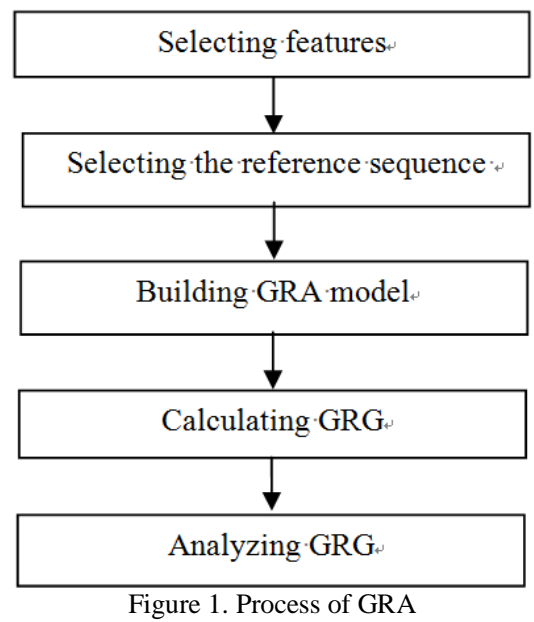

Step 1 Select features

After some investigations, whether the peasants are willing to participate in rural land circulation (RLC) depends on three factors: the income, the risk, and the safeguard of RLC. Through research and analysis, the following nine items of three types are selected as the indexes influencing RLC.

1) The income of RLC: The net income of circulation peasant (NICP) $x_{1}$, non-agricultural income rate (NAIR) $x_{2}$, and the ratio of before and after the income of circulation (RBAIC) $x_{3}$.

2) The risk of RLC: The loss probability of the peasant who contracted land (LPPCL) $x_{4}$, the violation probability of rural land circulation (VPRLC) $x_{5}$, the ratio of signed contracts (RSC) $x_{6}$, and the ratio of peasants spontaneously taking part in rural land circulation (PPSRLC) $x_{7}$.

3) The security of RLC: The reemployment probability of the rural land circulation peasants (RPRLCP) $x_{8}$ and the guarantee rate of foodstuff security (GRFS) $x_{9}$.

The feature sequence is $X=\left(x_{1}, x_{2}, \cdots, x_{9}\right)$.

\section{Step 2 Build a GRA model}

Take for example the relevant data of Longhui, Dongkou, Wugnag of Hunan province from 2004 to 2009, which is shown in Table 1. Supposing the ratio of rural land circulation (RRLC) (the area of RLC / the total area of rural land) is the reference sequence $X_{0}$ and the nine factors are the objective sequences $X_{i}$, T-GRG, Deng's GRG, GARG, and GSRG are chosen as the calculation model.

The reference sequence:

$$
X_{0}=(0.221,0.224,0.232,0.237,0.243,0.248)
$$


Table 1. The value of influence factors of rural land circulation

\begin{tabular}{|c|c|c|c|c|c|c|}
\hline $\begin{array}{ll}\text { Factors } & \text { Year } \\
\end{array}$ & 2004 & 2005 & 2006 & 2007 & 2008 & 2009 \\
\hline RRLC $x_{0}$ & 0.221 & 0.224 & 0.232 & 0.237 & 0.243 & 0.248 \\
\hline $\mathrm{NICP} x_{1}$ & 3850 & 4000 & 4350 & 4580 & 4730 & 5200 \\
\hline NAIR $x_{2}$ & 0.69 & 0.70 & 0.71 & 0.71 & 0.75 & 0.79 \\
\hline RBAIC $x_{3}$ & 1.11 & 1.12 & 1.13 & 1.12 & 1.13 & 1.13 \\
\hline LPPCL $x_{4}$ & 0.09 & 0.10 & 0.11 & 0.13 & 0.12 & 0.10 \\
\hline VPRLC $x_{5}$ & 0.07 & 0.08 & 0.08 & 0.09 & 0.08 & 0.08 \\
\hline $\operatorname{RSC} x_{6}$ & 17.2 & 17.5 & 18.3 & 19.6 & 21.3 & 22.8 \\
\hline PPSRLC $x_{7}$ & 23.5 & 23.8 & 24.1 & 24.9 & 25.1 & 26.9 \\
\hline RPRLCP $x_{8}$ & 0.814 & 0.825 & 0.837 & 0.854 & 0.879 & 0.912 \\
\hline GRFS $x_{9}$ & 0.561 & 0.572 & 0.583 & 0.552 & 0.538 & 0.526 \\
\hline
\end{tabular}

The objective sequences:

$$
\begin{aligned}
& X_{1}=(3850,4000,4350,4580,4730,5200) \\
& X_{2}=(0.69,0.70,0.71,0.71,0.75,0.79) \\
& \vdots \\
& X_{9}=(0.561,0.572,0.583,0.552,0.538,0.526)
\end{aligned}
$$

Step 3 Calculate the grade

Calculate the relation grade between the factors and the rate of rural land circulation based on T-GRG, Deng's GRG, GARG, IGRG, and GSRG. The raw data uses the initial transformation method.

According to Tables 2-6, using the different relation grade model leads to different results. Non-dimension may affect the analysis. T-GRA and GSRG have isotonicity after being applied with the dimensionless methods, and T-GRA can reflect the negative correlation between factors.

According to Table 7, although the different non-dimension transformation methods lead to different gray relation grades, the orders of factors are approximately the same: $x_{8} \succ x_{3} \succ x_{7} \succ x_{2} \succ x_{6} \succ x_{1} \succ x_{9} \succ x_{5} \succ x_{4}$. Table 8 shows that different non-dimension transformation methods lead to different results. The order based on initial transformation is

$$
x_{8} \succ x_{7} \succ x_{2} \succ x_{3} \succ x_{6} \succ x_{9} \succ x_{5} \succ x_{1} \succ x_{4}
$$

The order based on mean transformation is

$$
x_{8} \succ x_{7} \succ x_{2} \succ x_{3} \succ x_{1} \succ x_{5} \succ x_{6} \succ x_{9} \succ x_{4}
$$

The order based on multiple transformation is

$$
x_{8} \succ x_{7} \succ x_{2} \succ x_{3} \succ x_{6} \succ x_{5} \succ x_{9} \succ x_{1} \succ x_{4}
$$

The order based on range maximization transformation is

$$
x_{8} \succ x_{7} \succ x_{2} \succ x_{6} \succ x_{3} \succ x_{5} \succ x_{1} \succ x_{9} \succ x_{4}
$$

Step 4 Analyze the GRG

To take all these factors into account, the rate of non-agricultural income, the rate of signed contracts, and the probability of peasants spontaneously taking part in rural land circulation have more influence on the rate of RLC. 
Table 2. T-GRA (whether possess non-dimension)

\begin{tabular}{|c|c|c|c|c|}
\hline Order & YES & Influence factors & No & Influence factors \\
\hline 1 & 0.7662 & NICP $x_{1}$ & 0.7654 & NICP $x_{1}$ \\
\hline 2 & 0.7522 & RPRLCP $x_{8}$ & 0.7522 & RPRLCP $x_{8}$ \\
\hline 3 & 0.6369 & RSC $x_{6}$ & 0.6371 & RSC $x_{6}$ \\
\hline 4 & 0.4983 & PPSRLC $x_{7}$ & 0.4987 & PPSRLC $x_{7}$ \\
\hline 5 & 0.4512 & NAIR $x_{2}$ & 0.4512 & NAIR $x_{2}$ \\
\hline 6 & 0.2873 & RBAIC $x_{3}$ & 0.2873 & RBAIC $x_{3}$ \\
\hline 7 & -0.1642 & GRFS $x_{9}$ & -0.1643 & GRFS $x_{9}$ \\
\hline 8 & 0.1229 & LPPCL $x_{4}$ & 0.1234 & LPPCL $x_{4}$ \\
\hline 9 & 0.0446 & VPRLC $x_{5}$ & 0.0444 & VPRLC $x_{5}$ \\
\hline
\end{tabular}

Table 3. Deng's GRA (whether possess non-dimension)

\begin{tabular}{|c|c|c|c|c|}
\hline Order & YES & Influence factors & No & Influence factors \\
\hline 1 & 0.9466 & RPRLCP $x_{8}$ & 1.0000 & LPPCL $x_{4}$ \\
\hline 2 & 0.9272 & PPSRLC $x_{7}$ & 0.9999 & VPRLC $x_{5}$ \\
\hline 3 & 0.9222 & NAIR $x_{2}$ & 0.9999 & GRFS $x_{9}$ \\
\hline 4 & 0.8187 & RBAIC $x_{3}$ & 0.9998 & RPRLCP $x_{8}$ \\
\hline 5 & 0.7823 & RSC $x_{6}$ & 0.9998 & NAIR $x_{2}$ \\
\hline 6 & 0.7774 & GRFS $x_{9}$ & 0.9997 & RBAIC $x_{3}$ \\
\hline 7 & 0.7389 & VPRLC $x_{5}$ & 0.9927 & RSC $x_{6}$ \\
\hline 8 & 0.7053 & NICP $x_{1}$ & 0.9907 & PPSRLC $x_{7}$ \\
\hline 9 & 0.6492 & LPPCL $x_{4}$ & 0.3702 & NICP $x_{1}$ \\
\hline
\end{tabular}

Table 4. GARG (whether possess non-dimension)

\begin{tabular}{|c|c|c|c|c|}
\hline Order & YES & Influence factors & No & Influence factors \\
\hline 1 & 0.9636 & PPSRLC $x_{7}$ & 0.9961 & RBAIC $x_{3}$ \\
\hline 2 & 0.9595 & NAIR $x_{2}$ & 0.9907 & VPRLC $x_{5}$ \\
\hline 3 & 0.9589 & RPRLCP $x_{8}$ & 0.9674 & LPPCL $x_{4}$ \\
\hline 4 & 0.8154 & NICP $x_{1}$ & 0.9296 & GRFS $x_{9}$ \\
\hline 5 & 0.8549 & RSC $x_{6}$ & 0.9284 & NAIR $x_{2}$ \\
\hline 6 & 0.8535 & RBAIC $x_{3}$ & 0.9110 & RPRLCP $x_{8}$ \\
\hline 7 & 0.8097 & VPRLC $x_{5}$ & 0.5464 & PPSRLC $x_{7}$ \\
\hline 8 & 0.8027 & GRFS $x_{9}$ & 0.5252 & RSC $x_{6}$ \\
\hline 9 & 0.7389 & LPPCL $x_{4}$ & 0.5001 & NICP $x_{1}$ \\
\hline
\end{tabular}

Table 5. GSRG (whether possess non-dimension)

\begin{tabular}{|c|c|c|c|c|}
\hline Order & YES & Influence factors & No & Influence factors \\
\hline 1 & 0.9919 & RPRLCP $x_{8}$ & 0.9919 & RPRLCP $x_{8}$ \\
\hline 2 & 0.9812 & RBAIC $x_{3}$ & 0.9812 & RBAIC $x_{3}$ \\
\hline 3 & 0.9811 & PPSRLC $x_{7}$ & 0.9811 & PPSRLC $x_{7}$ \\
\hline 4 & 0.9802 & NAIR $x_{2}$ & 0.9802 & NAIR $x_{2}$ \\
\hline 5 & 0.9696 & RSC $x_{6}$ & 0.9696 & RSC $x_{6}$ \\
\hline 6 & 0.9663 & NICP $x_{1}$ & 0.9663 & NICP $x_{1}$ \\
\hline 7 & 0.9635 & GRFS $x_{9}$ & 0.9635 & GRFS $x_{9}$ \\
\hline 8 & 0.9267 & VPRLC $x_{5}$ & 0.9267 & VPRLC $x_{5}$ \\
\hline 9 & 0.8944 & LPPCL $x_{4}$ & 0.8944 & LPPCL $x_{4}$ \\
\hline
\end{tabular}


Table 6. IGRG (whether possess non-dimension)

\begin{tabular}{|c|c|c|c|c|}
\hline Order & YES & Influence factors & No & Influence factors \\
\hline 1 & 0.8788 & RSC $x_{6}$ & 0.8299 & RPRLCP $x_{8}$ \\
\hline 2 & 0.8598 & NICP $x_{1}$ & 0.6748 & PPSRLC $x_{7}$ \\
\hline 3 & 0.5325 & LPPCL $x_{4}$ & 0.6633 & NAIR $x_{2}$ \\
\hline 4 & 0.4876 & NAIR $x_{2}$ & 0.6013 & RSC $x_{6}$ \\
\hline 5 & 0.3551 & VPRLC $x_{5}$ & 0.5016 & LPPCL $x_{4}$ \\
\hline 6 & 0.2784 & PPSRLC $x_{7}$ & 0.5006 & RBAIC $x_{3}$ \\
\hline 7 & 0.2712 & RPRLCP $x_{8}$ & 0.4216 & NICP $x_{1}$ \\
\hline 8 & 0.2153 & GRFS $x_{9}$ & 0.3359 & VPRLC $x_{5}$ \\
\hline 9 & 0.0089 & RBAIC $x_{3}$ & 0.3337 & GRFS $x_{9}$ \\
\hline
\end{tabular}

Table 7. The GSRG based on the different non-dimension transformation methods

\begin{tabular}{|c|c|c|c|c|}
\hline Factors & IT & MT & MULT & RMT \\
\hline$x_{1}$ & 0.9663 & 0.9644 & 0.9571 & 60.9712 \\
\hline$x_{2}$ & 0.9802 & 0.9793 & 0.9783 & 40.9810 \\
\hline$x_{3}$ & 0.9812 & 0.9809 & 0.9797 & 20.9822 \\
\hline$x_{4}$ & 0.8944 & 0.8910 & 0.8714 & 90.9077 \\
\hline$x_{5}$ & 0.9267 & 0.9241 & 0.9152 & 80.9313 \\
\hline$x_{6}$ & 0.9696 & 0.9672 & 0.9616 & 50.9738 \\
\hline$x_{7}$ & 0.9811 & 0.9801 & 0.9791 & 30.9816 \\
\hline$x_{8}$ & 0.9919 & 0.9916 & 0.9912 & 10.9921 \\
\hline$x_{9}$ & 0.9635 & 0.9635 & 0.9616 & 70.9653 \\
\hline
\end{tabular}

Table 8. Deng's GRA based on the different non-dimension transformation methods

\begin{tabular}{|c|c|c|c|c|}
\hline Factors & IT & MT & MULT & RMT \\
\hline$x_{1}$ & 0.7053 & 0.6897 & 80.7053 & 70.7073 \\
\hline$x_{2}$ & 0.9222 & 0.8648 & 30.9222 & 30.8990 \\
\hline$x_{3}$ & 0.8187 & 0.7478 & 40.8187 & 50.7805 \\
\hline$x_{4}$ & 0.6492 & 0.5497 & 90.6492 & 90.6275 \\
\hline$x_{5}$ & 0.7389 & 0.6589 & 60.7389 & 60.7431 \\
\hline$x_{6}$ & 0.7823 & 0.6531 & 50.7823 & 40.7919 \\
\hline$x_{7}$ & 0.9272 & 0.8747 & 20.9272 & 20.9043 \\
\hline$x_{8}$ & 0.9466 & 0.9055 & 10.9466 & 10.9303 \\
\hline$x_{9}$ & 0.7774 & 0.6055 & 70.7357 & 80.6729 \\
\hline
\end{tabular}

\section{Conclusions}

The main driving factors on Chinese rural land circulation management obtained by data analysis of hybrid information based on different gray relation algorithmic models. The analysis results present there are three main driving factors affecting the rural land circulation in China, which are the rate of non-agricultural income, the ratio of signed contracts and the ratio of peasants' spontaneous taking part in rural land circulation). It is effective and efficient for gray relation algorithms to obtain the most influential driving factors on the rural land circulation in China based on our collected samples.

The data analysis results also illustrate that different gray relation algorithms (i.e., the Deng's gray relation analysis model, gray absolute relation analysis model, T-type gray relation analysis model, improved gray relation analysis model and gray slope relation analysis model) may affect the order of the importance of each driving factor. In the future work, in order to obtain a more exact solution, the evidence fusion theory can be used to fuse the analysis results obtained by different gray relation algorithmic models. 


\section{References}

1. S. F. Liu, J. Forrest, and Y. J. Yang, “A Brief Introduction to Grey Systems Theory,” Grey Systems: Theory and Application, Vol. 2, No. 2, pp. 89-104, 2012

2. J. H. Zhao, B. Li, J. H. Zhang, and C. C. Wang, "Research into Effect Evaluation Method of Complex Electromagntic Spectrum Management Plan," Shipboard Electronic Countermeasure, Vol. 40, No. 3, pp. 35-39, 2017

3. S. Dong, Q. Xia, and N. Li, "Research on Software Defect List: Prediction Method based on Grey Relational Analysis," Computer Engineering and Application, Vol. 42, pp. 67-71, 2013

4. X. Zhou, "The Study on Grey Relational Degree and Its Application,” Jilin University Press, 2007

5. J. L. Deng, "Grey System," China Ocean Press, Beijing, 1988

6. J. C. Li, D. Y. Bi, Y. L. Ying, K. Wei, and B. Zhang, "An Improved Algorithm for Extracting Subtle Features of Radiation Source Individual Signals,” Electronics, Vol. 8, No. 2, pp. 246, 2019

7. Q. Wang, "The Grey Relational Analysis of B-Mode," Journal of Huazhong University of Science and Technology, Vol. 6, pp. 77-82, 1989

8. Z. Mei, "The Concept and Computation Method of Grey Absolute Correlation Degree," Systems Engineering, Vol. 5, pp. 43-44, 1992

9. Y. Lin, C. Wang, C. G. Ma, Z. Dou, and X. F. Ma, "A New Combination Method for Multi-Sensor Conflict Information,” The Journal of Supercomputing, Vol. 72, pp. 1-17, 2016

10. W. Tang, "The Concept and the Computation Method of T's Correlation Degree," Application of Statistics and Management, Vol. 1, pp. 34-37, 1995

11. Y. Dang, "The Research of Grey Slope Relational Grade," System Sciences and Comprehensive Studies in Agriculture, Supplement 10, pp. 331-337, 1994

12. J. Li, Y. Ying, Y. Ren, et al., "Research on Rolling Bearing Fault Diagnosis based on Multi-Dimensional Feature Extraction and Evidence Fusion Theory," Royal Society Open Science, 2019

13. Y. Sun and Y. Dang, "The Improved Model of Grey Slope Relational Grade," Statistics and Decision, Vol. 15, pp. 12-13, 2007

14. Q. Wang and L. Guo, "Generalized Relational Analysis Method," Journal of Huazhong University of Science and Technology (Natural Science Edition), Vol. 8, pp. 97-99, 2005

15. S. Zhang, "Comparison between Computation Models of Grey Interconnect Degree and Analysis on Their Shortages," Systems Engineering, Vol. 3, pp. 45-49, 1996

16. X. Li, "Research on the Computation Model of Grey Interconnect Degree," Systems Engineering, Vol. 6, pp. 58-61, 1995

17. L. Yun, C. Wang, J. X. Wang, and Z. Dou, "A Novel Dynamic Spectrum Access Framework based on Reinforcement Learning for Cognitive Radio Sensor Networks," Sensors, Vol. 16, pp. 1-22, 2016

18. M. Li, “A New Descriminant Byelaw for Grey Interconnect Degree and Its Calculation Formulas," Systems Engineering, Vol. 1, pp. 68-70, 1998

19. F. Lu, X. Liu, and Q. Liu, "The Theory of Grey Relative Analysis and It's New Research," Journal of Wuhan University of Technology, Vol. 2, pp. 41-43, 2000

20. J. Li and Y. Ying, "A Method to Improve the Robustness of Gas Turbine Gas-Path Fault Diagnosis Against Sensor Faults," IEEE Transactions on Reliability, Vol. 67, No. 1, pp. 3-12, 2018

21. H. Wang, J. C. Li, L. L. Guo, Z. Dou, Y. Lin, and R. L. Zhou, "Fractal Complexity-based Feature Extraction Algorithm of Communication Signals," Fractals-Complex Geometry Patterns \& Scaling in Nature \& Society, Vol. 25, pp. 1740008, 2017

22. N. Shui, T. Dong, and Z. Sha, "On Several Theoretical Problems of Grey Correlation Degree," Systems Engineering, Vol. 6, pp. 23-26, 1992

23. Y. Huang and Z. Chen, "The Inconsistent Problems in the Grey Relational Theory," Systems Engineering -Theory \& Practice, Vol. 8, pp. 118-121, 2003

24. X. Xiao and H. Fu, "Analysis on the Correlation Measurement of Shipping Exchange and Port Economy," Logistics Sci-Tech, No. 10 , pp. 72-74, 2017

25. G. K. Bose, "Selecting Significant Process Parameters of ECG Process using Fuzzy-MCDM Technique," International Journal of Materials Forming and Machining Processes (IJMFMP), Vol. 2, No. 1, pp. 38-53, 2015

26. M. Wei and Y. Liu, "Information System Security Risk Assessment based on Grey Relational Analysis and Dempster-Shafer Theory," in Proceedings of International Conference on Mechatronic Science, Electric Engineering and Computer, pp. 853-856, 2011

27. P. Hsu and E. Lin, "Tsai C W. Optimal Selection of Business Managers for Integrated Marketing Communications Companies Using AHP and GRA," International Journal of Customer Relationship Marketing and Management (IJCRMM), Vol. 7, No. 2, pp. 16-29, 2016

28. C. Fu, J. Zheng, and J. Zhao, "Application of Grey Relational Analysis for Corrosion Failure of Oil Tubes," Corrosion Science, pp. 881-889, 2001

29. L. Abhang and M. Hameedullah, "Response Surface Modeling and Grey Relational Analysis to Optimize Turning Parameters with Multiple Performance Characteristics," International Journal of Manufacturing, Materials, Vol. 2, No. 2, pp. 12-45, 2012

30. A. R. Otero, A. Ejnioui, C. E. Otero, and G. Tejay, "Evaluation of Information Security Controls in Organizations by Grey Relational Analysis," International Journal of Dependable and Trustworthy Information Systems (IJDTIS), Vol. 2, No. 3, pp. 36-54, 2011

31. H. B. Li, M. S. Yang, Y. Li, Q. L. Yuan, and Z. M. Yao, "Optimization of SPIF Surface Roughness via Grey Relational Analysis," Mechanical Science and Technology for Aerospace Engineering, Vol. 236, No. 10, pp. 1576-1581, 2017

32. W. Liu and Z. Li, "The Grey Relational Analysis about the Influence Factors of Rural Land Circulation," Social Sciences in 
Hunan, Vol. 3, pp. 136-138, 2012

33. J. Deng, "The Basic Method of Grey System Theory," Huazhong University of Science and Technology Press, Wuhan, 2002

34. F. Li, "Theoretical Study and Application on Grey System Theory," Science \& Technology Literature Press, Beijing, 1992

35. M. X. Cao, "Research on Grey Incidence Analysis Model and Its Application," Nanjing University of Aeronautics and Astronautics, 2007

36. J. Li, Y. Ying, X. Lou, J. Fan, Y. Chen, and D. Bi, "Integrated Energy System Optimization based on Standardized Matrix Modeling Method," Applied Sciences, Vol. 8, No. 12, pp. 2372, 2018

37. Y. Ying, J. Li, Z. Chen, and J. Guo, "Study on Rolling Bearing on-Line Reliability Analysis based on Vibration Information Processing," Computers \& Electrical Engineering, No. 69, pp. 842-851, 2018

38. J. Deng, "The Basic Method of Grey System Theory," Huazhong University of Science and Technology Press, Wuhan, 1992

39. Z. Liu, "Two Problems Existing in Grey Systems Analysis," Systems Engineering-Theory \& Practice, Vol. 20, No. 9, pp. 123124,2000

40. F. Lv, "Research on the Identification Coefficient of Relational Grade for Grey System," Systems Engineering -Theory \& Practice, Vol. 6, pp. 49-54, 1997

41. X. Li, "Research on the Computation Model of Grey Interconnect Degree," Systems Engineering, Vol. 6, pp. 58-61, 1995 